\title{
Effects of Dietary Supplementation of Salvia officinalis L. in Organic Laying Hens on Egg Quality, Yolk Oxidative Stability and Eggshell Microbiological Counts
}

\author{
Dimitrios Galamatis ${ }^{1,2, *}$, Georgios A. Papadopoulos ${ }^{1} \oplus$, Diamanto Lazari ${ }^{3}{ }^{\circledR}$, Dimitrios Fletouris ${ }^{4}$, \\ Evanthia Petridou ${ }^{5}\left(\mathbb{D}\right.$, Georgios I. Arsenos ${ }^{1}(\mathbb{D})$ and Paschalis Fortomaris ${ }^{1}(\mathbb{D}$ \\ 1 Laboratory of Animal Husbandry, Faculty of Veterinary Medicine, School of Health Sciences, \\ Aristotle University of Thessaloniki, 54124 Thessaloniki, Greece; geopaps@vet.auth.gr (G.A.P.); \\ arsenosg@vet.auth.gr (G.I.A.); fortomap@vet.auth.gr (P.F.) \\ 2 Hellenic Agricultural Organization DIMITRA (ELGO DIMITRA), General Management Assurance of \\ Agricultural Products Quality, Kifissias 33 Str., 54248 Thessaloniki, Greece \\ 3 Laboratory of Pharmacognosy, Faculty of Pharmacy, School of Health Sciences, Aristotle University of \\ Thessaloniki, 54124 Thessaloniki, Greece; dlazari@pharm.auth.gr \\ 4 Laboratory of Milk Hygiene and Technology, Faculty of Veterinary Medicine, School of Health Sciences, \\ Aristotle University of Thessaloniki, 54124 Thessaloniki, Greece; djflet@vet.auth.gr \\ 5 Laboratory of Microbiology, Faculty of Veterinary Medicine, School of Health Sciences, Aristotle University of \\ Thessaloniki, 54124 Thessaloniki, Greece; epetri@vet.auth.gr \\ check for \\ updates \\ * Correspondence: galamatis@elog.gr; Tel.: +30-639-227-5112
}

Citation: Galamatis, D.;

Papadopoulos, G.A.; Lazari, D.; Fletouris, D.; Petridou, E.;

Arsenos, G.I.; Fortomaris, P. Effects of Dietary Supplementation of Salvia officinalis L. in Organic Laying Hens on Egg Quality, Yolk Oxidative

Stability and Eggshell Microbiological Counts. Animals 2021, 11, 2502. https://doi.org/10.3390/ ani11092502

Academic Editors: Natalie Morgan and Youssef A. Attia

Received: 23 July 2021

Accepted: 23 August 2021

Published: 26 August 2021

Publisher's Note: MDPI stays neutral with regard to jurisdictional claims in published maps and institutional affiliations.

Copyright: (c) 2021 by the authors. Licensee MDPI, Basel, Switzerland. This article is an open access article distributed under the terms and conditions of the Creative Commons Attribution (CC BY) license (https:// creativecommons.org/licenses/by/ $4.0 /)$.
Simple Summary: Organic laying hen systems are considered welfare-friendly, because hens are raised mainly outdoors under natural conditions. The notion is that eggs produced in those systems are better in terms of quality. Research has found that aromatic plants and their extracts can tackle many of the latter challenges when added to poultry diets due to their antioxidant and antimicrobial effects. The current study investigated the effects of a dietary supplementation of Salvia officinalis L. in organically raised laying hens during two experimental periods. The results showed improved oxidative stability of the eggs and reduced microbial counts in the eggshells. The egg quality parameters were partly affected, with the yolk weight showing the largest differences between treatments.

Abstract: Aromatic plants of Labiatae family are used in poultry diets because of their antimicrobial and antioxidant activity. The notion is that hens raised in organic systems face several health and environmental challenges. Hence, the objective here was to assess hens' performances and the quality of their eggs in such systems following a dietary supplementation of Salvia officinalis L. in powder form. The experiments were conducted over two successive years ( 1 and 2$)$. They lasted 16 weeks each and involved 198 laying hens aged 40 weeks old randomly assigned to three groups: Con (control diet), Sal-0.5\%, and Sal-1.0\% (diets supplemented with Salvia officinalis L. at $0.5 \%$ or 1.0\%, respectively). The malondialdehyde (MDA) levels in egg yolks in year 2 were lower in both Sal-0.5\% and Sal-1.0\% compared to the Con $(p<0.05)$. The total number of Enterobacteriaceae in eggshells were lower in Sal-1.0\% compared to the Con $(p<0.05)$ in both years. The results suggest that a dietary supplementation of Salvia officinalis L. at $1.0 \%$ improves the antioxidant status and reduces the microbial load of eggs produced in organic systems.

Keywords: organic; aromatic plants; laying hens; Salvia officinalis L.; malondialdehyde (MDA); Enterobacteriaceae

\section{Introduction}

Egg production systems have evolved because of continuous efforts to ensure the health, balanced nutrition, and wellbeing of birds. Commercial egg production systems comprise confined systems, free range, and organic. The latter are considered as the ones 
providing the highest welfare status by both egg consumers and the public. Consumers' knowledge and perception of egg production systems prioritizes animal welfare and dictates their purchasing decisions [1]. The prevailing view is that laying hens in freerange systems enjoy improved welfare compared to those housed indoors [2]. Free-range systems provide birds' natural conditions to express their behaviors [3], and their eggs are considered as better in terms of quality [4]. However, it has been documented that a major challenge in these systems is the management of health-related issues [5], while in organic eggs, production welfare issues are under debate [6]. Furthermore, the evaluation of microbial contamination is also used to assess the egg quality [7]. Eggshells derived from alternative housing systems have been identified with a higher level of microorganisms than the ones collected from cage systems [7]. Thus, there is a necessity to produce eggs from organic systems with limited microbial contamination.

The ban of antibiotics as growth promoters (AGP) in animal feeds by the EU [8] forced research to seek alternative methods to cater the need of improving animal performances in livestock systems. The latter also became a priority in organic poultry production, seeking alternatives to control diseases and improve bird performances [9]. Hence, phytogenic feed additives, organic acids, and probiotics became the favorable nonantibiotic growth promoters considering their established use in animal nutrition [10]. Probiotic supplementation in organic laying hens' diets influenced positively in the gut of hens the counts of beneficial bacteria such as Lactobacillus spp. and Bifidobacterium spp. and reduced the counts of harmful bacteria such as E. coli, clostridia, and staphylococci [11]. In the latter study, however, the level of eggshell contamination was not evaluated.

Essential oils and botanicals could serve the same scope as feed ingredients [12]. There is abundant evidence in the literature that aromatic plants and their extracts have antioxidant $[9,13]$ and antimicrobial effects [14-16] following their supplementation in poultry diets. Moreover, such dietary supplements have a positive impact on the gastrointestinal function and nutrient digestibility [17]. Aromatic plants of the Labiatae family have been used in poultry diets due to their antimicrobial and antioxidant activity [9]. According to Bozkurt et al. [18], Salvia officinalis L., thyme, and oregano are among the most promising plants of the Labiatae family. The supplementation of Salvia officinalis L. extracts in roosters' diets had positive effects on the quantity and quality of the sperm produced, while it increased the testosterone levels [19]. The dietary supplementation of such an extract reduced the Salmonella counts in the liver, spleen, and cecum of broilers infected with Salmonella enteritidis [20]. Levkut et al. [21] and Farhadi et al. [22] showed that the incorporation of Salvia officinalis L. extract in the broilers' diet significantly improved their average daily gain and other performance parameters, whereas, in another study, Ryzner et al. [23] showed that it reduced the oxidative stress parameters evaluated in the red blood cells and kidneys of broilers. Recently, the supplementation of Salvia officinalis L. aqueous leaf extract in broilers' diets enhanced the immunity response of broilers and significantly reduced the ileal counts of E. coli [24]. Elsewhere, the supplementation of Salvia officinalis essential oil in laying strain chicks' diets showed that, when supplemented at lower concentrations, the antioxidant defense mechanisms were improved by the induction of antioxidant enzymes [25].

Considering the available literature, the evidence for the use of Salvia officinalis L. in the diets of organic laying hens is limited. Hence, the objective of the present study was to assess the egg quality parameters, oxidative stability of egg yolks, and microbial counts of eggshells of organically raised laying hens following the dietary supplementation of Salvia officinalis L. in powder form.

\section{Materials and Methods}

\subsection{Animals and Housing}

The experiment was conducted on a commercial organic laying hen farm located in Vasilika Village of Thessaloniki Prefecture, Central Macedonia, Greece. The farm was established in 1994 and started its commercial operation in 1996. Hy-Line Brown laying 
hens were housed under a free-range system in multiple buildings of the farm covering an area of $1500 \mathrm{~m}^{2}$. All hens had outdoor access to a field of $25,000 \mathrm{~m}^{2}$ planted with olive trees. The farm also had $200,000 \mathrm{~m}^{2}$ of cultivated land with cereals and other feeds following the organic agriculture guidelines used in the hens' diet. All the feeds were formulated and produced in the mill of the farm. The farm organic registration code is 0EL54035. Organic certification was provided and monitored by an independent organization, "Physiologike" (https:/ / physiologike.gr/; (accessed on 20 February 2021), according to EN ISO/IEC 17065.

\subsection{Experimental Facility}

Laying hens were housed in a designated chamber with the dimensions $6 \mathrm{~m} \times 12 \mathrm{~m}$, covering a surface of $72 \mathrm{~m}^{2}$. The indoor facility was split into 6 compartments (dimensions $2 \mathrm{~m} \times 4.2 \mathrm{~m}$ ), each one covering a surface of $8.4 \mathrm{~m}^{2}$. The compartments were constructed and separated using a portable wooden structure together with a plastic net. Each compartment had an egg nest with 8 available places (1 place per 3 laying hens), a conic feeder with a capacity of $25 \mathrm{~kg}$, and a bell type drinker with a diameter of $38 \mathrm{~cm}$ (Plasson Livestock, Maagan Michael, D.N. Menashe 3780500, Israel). To enable outdoor access for all laying hens, each compartment had a specially constructed square pop hole with the dimensions of $0.5 \mathrm{~m} \times 0.5 \mathrm{~m}$. Moreover, each compartment had a door to allow access to personnel for the everyday husbandry practices, e.g., egg collection and feed renewal (Figure 1). The designated chamber had 3 windows, with dimensions of $1.8 \mathrm{~m}$ length $\times 0.8 \mathrm{~m}$ height, to ensure proper air circulation. The chamber walls and all equipment used were pressure washed and disinfected before the start of each experiment. Sawdust was used for bedding. An 8-h darkness period was set, with the duration of physical light about $6 \mathrm{~h}$, on average.

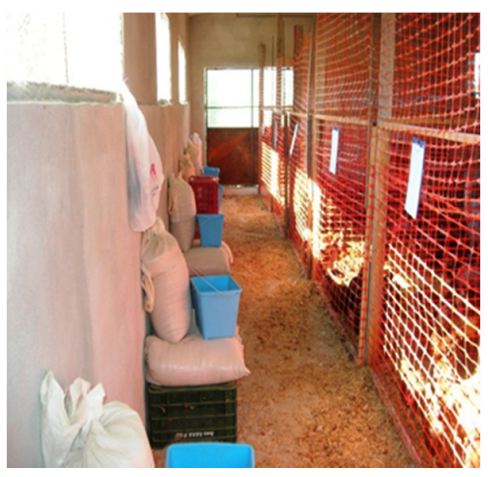

(a)

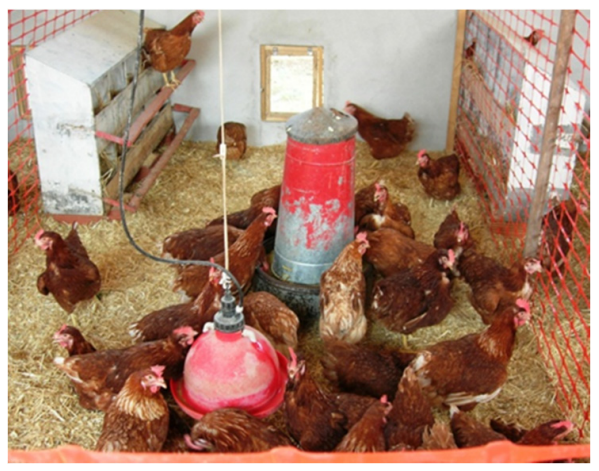

(b)

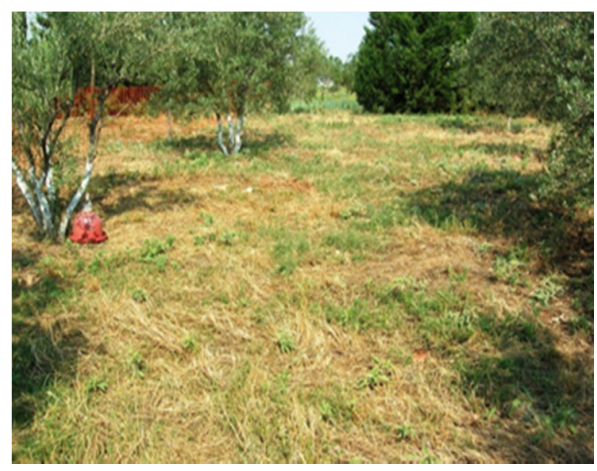

(c)

Figure 1. Indoor and outdoor parts of the experimental facility used in the study. (a) Corridor in front of the 6 experimental compartments. Experimental diets were kept in front of each respective compartment. (b) Inside view of an experimental compartment. Each compartment contained an egg nest with 8 available places, a conic feeder, and a bell-type drinker. A square pop hole enabled outdoor access of the laying hens. (c) Outside view of the field planted with olive trees in which laying hens had access. Bell-type drinkers were also placed in the field.

In each experiment, $198 \mathrm{Hy}$-Line brown laying hens approximately 40 weeks old were used. The laying hens were randomly assigned to 3 experimental groups $(n=66$ per group; 2 pens of 33 laying hens per group) as follows: (i) group Con: hens were fed the standard organic diet and served as the control group, (ii) group Sal- $0.5 \%$ : hens were fed the standard organic diet supplemented with dehydrated Salvia officinalis L. in powder form at the level of $0.5 \%$, and (iii) group Sal-1.0\%: hens were fed the standard organic diet supplemented with dehydrated Salvia officinalis L. in powder form at the level of $1.0 \%$. The study was subdivided into two successive phases. The duration of each experimental phase was 16 weeks and started in July and ended in November of the same year. The weather data of the area where the farm is located were collected from the Hellenic National Meteorological Service (http: / / www.hnms.gr; accessed on 20 February 2021). The meteorological data 
analysis of the study period showed a higher average temperature and a lower average precipitation rate during the first experimental period (year 1).

\subsection{Ethics Approval Statement and Experimental Design}

The research protocol of the study was part of a PhD project of DG and was approved by the General Assembly of the Veterinary Faculty of Aristotle University of Thessaloniki. The General Assembly of the Veterinary Faculty of Aristotle University of Thessaloniki approved the specific PhD protocol in its decision: 55/27-5-2015.

\subsection{Ingredient Sources, Diet Formulation, and Analysis}

Salvia officinalis L., used in the present study, originated from plants that were cultivated in a field in Western Macedonia, Greece. The harvest was made each year at the beginning of June after blossom. The harvested plants were placed in designated buildings that allowed natural drying, a process that lasted approximately 15 days. Sprouts, leaves, and flowers were subsequently ground into a powder form and stored for future use in the experiment. Table 1 shows the main ingredients of the experimental diets and their nutrient analysis. The proximate analysis and chemical composition of the diets are provided in Table 2, whereas Table 3 shows the chemical composition (\%) of the Salvia officinalis L. extract used in the experiment. The essential oil of Salvia officinalis L. was analyzed at the Laboratory of Pharmacognosy, School of Pharmacy, Faculty of Health Sciences, Aristotle University of Thessaloniki. The dried and powdered leaves of the plant, which were received by the company "DIOSKOURIDIS", were subjected to water distillation for two hours in a Clevenger apparatus according to Europaea Pharmacopeia and connected to a modified refrigerated container of essential oils. Additional cooling was used in order to reduce the byproducts of the heat treatment. After distillation, the essential oil was taken up in $2 \mathrm{~mL}$ of pentane (GC grade) and filtered through anhydrous sodium sulfate to dehydrate it. The obtained essential oil was kept at $-4{ }^{\circ} \mathrm{C}$ until it was analyzed. The essential oil yield was expressed in $\mathrm{mL} \cdot 100^{-1} \mathrm{~g}$ d.w. Essential oil analyses were performed on a Shimadzu GC-2010-GCMS-QP2010 system operating at $70 \mathrm{eV}$. This was equipped with a split/spitless injector $\left(230^{\circ} \mathrm{C}\right)$ and a fused silica HP-5 MS capillary column $(30 \mathrm{~m} \times 0.25 \mathrm{~mm}$ i.d., film thickness $0.25 \mu \mathrm{m})$. The temperature program was from $50-290{ }^{\circ} \mathrm{C}$ at a rate of $4{ }^{\circ} \mathrm{C} / \mathrm{min}$. Helium was used as a carrier gas at a flow rate of $1.0 \mathrm{~mL} / \mathrm{min}$. The injection volume of each sample was $1 \mu \mathrm{L}$. The retention indices (RI) for all the compounds were determined according to Van den Dool and Kratz [26], using n-alkanes as the standards. The identification of the components was based on a comparison of their mass spectra with those of NIST21 and NIST107 [27] and by comparison of their retention indices with the literature data [28]. The essential oils were often subjected to co-chromatography with authentic compounds (Fluka, Sigma).

The cultivated Salvia officinalis L. had a $2.37 \%$ extract concentration with the following basic components:

- $\quad$ cis- or $\alpha$-Thujone (33.80\%),

- $\quad$ trans- or $\beta$-Thujone $(6.97 \%)$,

- $\quad 1,8$-Cineole (=Eucalyptol) (11.61\%), and

- Camphor (24.54\%).

Approximately $98.95 \%$ of the composition of the extract was identified, and of 36 active substances, the concentration was analyzed (Table 3). 
Table 1. Gross ingredient composition ( $\mathrm{kg} / 1000 \mathrm{~kg}$, as fed basis) of the experimental laying hen diets Con (control diet), Sal-0.5\%, and Sal-1.0\% (diets supplemented with Salvia officinalis L. at 0.5\% or $1.0 \%$, respectively).

\begin{tabular}{cccc}
\hline Ingredients & \multicolumn{3}{c}{ Treatments } \\
\cline { 2 - 4 } & Con & Sal-0.5\% & Sal-1.0\% \\
\hline Corn & 518 & 510 & 505 \\
Soybean-44\%CP & 238 & 240 & 242 \\
Barley & 100 & 98 & 93 \\
Limestone & 104.4 & 104.4 & 104.4 \\
Monocalcium Phosphate & 9.5 & 9.5 & 9.5 \\
DL-Methionine & 1.5 & 1.5 & 1.5 \\
Choline & 0.5 & 0.5 & 0.5 \\
1 Premix & 2 & 2 & 2 \\
Soybean oil & 22 & 25 & 28 \\
Salvia officinalis L. & 0 & 5 & 2.3 \\
Sodium carbonate & 2.3 & 2.3 & 1.8 \\
Salt & 1.8 & 1.8 & 0 \\
\hline
\end{tabular}

${ }_{1}^{1}$ per $\mathrm{kg}$ of diet: vitamin A, 10,000 I.U.; vitamin D3, 2500 I.U; vitamin E, $30 \mathrm{mg}$; vitamin K, $4 \mathrm{mg}$; vitamin B1, $1 \mathrm{mg}$ vitamin B2, $5 \mathrm{mg}$; vitamin B6, $3 \mathrm{mg}$; vitamin B12, $0.02 \mathrm{mg}$; vitamin B3, $30 \mathrm{mg}$; vitamin B5, $10 \mathrm{mg}$; folic acid, $1 \mathrm{mg}$; biotin, $0.05 \mathrm{mg}$; vitamin C, $10 \mathrm{mg}$; choline, $400 \mathrm{mg}$; cobalt, $0.20 \mathrm{mg}$; copper, $10 \mathrm{mg}$; iodine, $1 \mathrm{mg}$; iron, $40 \mathrm{mg}$; manganese, $120 \mathrm{mg}$; selenium, $0.30 \mathrm{mg}$, zinc, $100 \mathrm{mg}$.

Table 2. Proximate analysis and chemical composition of the experimental diets of experimental laying hen diets: the Con (control diet), Sal-0.5\%, and Sal-1.0\% (diets supplemented with Salvia officinalis L. at $0.5 \%$ or $1.0 \%$, respectively).

\begin{tabular}{cccc}
\hline & \multicolumn{3}{c}{ Treatments } \\
\cline { 2 - 4 } Nutrients & Con & Sal-0.5\% & Sal-1.0\% \\
\hline Crude protein & 15.6 & 15.6 & 15.6 \\
Crude fat & 4.69 & 4.97 & 5.24 \\
Crude fiber & 3.08 & 3.07 & 3.06 \\
Total calcium & 4.17 & 4.17 & 4.17 \\
Total phosphorus & 0.51 & 0.51 & 0.51 \\
Available phosphorus & 0.32 & 0.32 & 0.32 \\
Metabolizable Energy (Kcal/kg) & 2808 & 2805 & 2803 \\
Lysine & 0.83 & 0.83 & 0.83 \\
Methionine & 0.41 & 0.41 & 0.41 \\
Methionine-Cystine & 0.68 & 0.68 & 0.68 \\
Threonine & 0.6 & 0.6 & 0.6 \\
Tryptophan & 0.18 & 0.18 & 0.18 \\
Sodium & 0.15 & 0.15 & 0.15 \\
Chloride & 0.14 & 0.14 & 0.14 \\
\hline
\end{tabular}

Table 3. Chemical composition (\%) of Salvia officinalis L. essential oil used in the experiment.

\begin{tabular}{cccc}
\hline Chemical Compounds & RI $^{\mathbf{a}}$ & $\mathbf{\%}$ & Method $^{\mathbf{b}}$ \\
\hline Tricyclene & 920 & $\operatorname{tr}$ & AI, MS \\
$\alpha$-Thujene & 926 & $\operatorname{tr}$ & AI, MS \\
$\alpha$-Pinene & 932 & 2.47 & AI, MS, Co-GC \\
Camphene & 946 & 2.46 & AI, MS \\
$\beta$-Pinene & 974 & 1.04 & AI, MS, Co-GC \\
$\beta$-Myrcene & 992 & 0.64 & AI, MS, Co-GC \\
$\alpha$-Phellandrene & 1004 & 0.06 & AI, MS \\
$\alpha$-Terpinene & 1016 & 0.11 & AI, MS \\
p-Cymene & 1024 & 0.51 & AI, MS, Co-GC \\
Limonene & 1028 & 1.54 & AI, MS \\
1,8-Cineole (=Eucalyptol) & 1030 & 11.61 & AI, MS, Co-GC \\
\hline
\end{tabular}


Table 3. Cont.

\begin{tabular}{cccc}
\hline$\gamma$-Terpinene & 1059 & 0.17 & AI, MS \\
trans-Linalool oxide (furanoid) & 1073 & $\operatorname{tr}$ & AI, MS \\
Terpinolene & 1088 & 0.19 & AI, MS \\
Linalool & 1100 & 0.34 & AI, MS, Co-GC \\
$\alpha$-Thujone & 1104 & 33.80 & AI, MS \\
$\beta$-Thujone & 1116 & 6.97 & AI, MS \\
$\alpha$-Campholenal & 1126 & $\operatorname{tr}$ & AI, MS \\
Isothujol & 1135 & 0.09 & AI, MS \\
cis-Sabinol & 1140 & 0.07 & AI, MS \\
Camphor & 1143 & 24.54 & AI, MS \\
Neoisothujol & 1150 & 0.07 & AI, MS \\
trans-Pinocamphone & 1161 & 0.10 & AI, MS \\
Borneol & 1165 & 2.93 & AI, MS, Co-GC \\
Menthol & 1173 & 0.08 & AI, MS \\
Terpinen-4-ol & 1177 & 0.56 & AI, MS, Co-GC \\
p-Cymen-8-ol & 1186 & 0.08 & AI, MS \\
$\alpha$-Terpineol & 1191 & 0.28 & AI, MS \\
Myrtenol & 1197 & 0.14 & AI, MS \\
Isobornyl acetate & 1286 & 1.73 & AI, MS \\
trans-Pinocarvyl acetate & 1294 & 0.23 & AI, MS \\
$\beta$-Caryophyllene & 1421 & 0.39 & AI, MS, Co-GC \\
$\alpha$-Caryophyllene & 1455 & 1.34 & AI, MS, Co-GC \\
Caryophyllene oxide & 1586 & 0.20 & AI, MS, Co-GC \\
Viridiflorol & 1594 & 3.07 & AI, MS \\
Humulene epoxide & 1612 & 0.96 & AI, MS
\end{tabular}

a HP-5MS column. ${ }^{\mathrm{b}}$ Identification method: RI = Retention Index determined on a HP-5 MS capillary column using a homologous series of n-alkanes (C9-C25), MS = mass spectrum, Co-GC = co-injection with authentic compound, and $\mathrm{tr}=$ traces, concentrations $<0.05$.

\subsection{Laying Hen Performance}

During both experimental periods, the feed intake of laying hens was measured on a weekly basis, and the average daily feed intake was calculated. The feed refusals and egg weight were recorded on a weekly basis to have an estimation of the average daily feed intake and egg mass production, respectively.

The daily egg production was also recorded for each experimental group by collecting eggs every morning (between 9:00-10:00 a.m.). The weekly egg-laying rate was expressed in $\%$ on a treatment basis. The feed conversion ratio was calculated by dividing the feed intake with the average egg weight for the respective periods and was expressed as $\mathrm{kg}$ of feed per kg of eggs produced. The individual body weight of hens was measured with a digital balance (Supra: SS3242, precision 5 g, Dinaksa Pesaje Industrial, Arrigorriaga-Vizcaya, Spain) at the start, the middle, and at the end of each experimental period.

\subsection{Egg Quality}

At weeks 2, 4, 6, 8, 10, 12, 14, and 16 of each experimental period, 12 eggs per treatment were collected to assess the egg quality parameters. The eggs were collected randomly from each treatment and weighed to calculate the average egg weight. The average egg mass was calculated on a weekly and on a pen basis by multiplying the egg weekly laying performance $(\%)$ with the average egg weight and dividing by 100: Egg mass $=($ Hen week $\%$ egg production * Egg Weight) $/ 100$. The eggs were weighed with a digital balance with 0.1-g accuracy (Navigator TM, N2B110, OHAUS Corporation, Parsippany, NJ, USA). The length and width of the eggs were measured with a digital caliper (EMC, LTD, China) with $0.01-\mathrm{mm}$ accuracy. The egg shape index was calculated using the formula: shape index $=($ width $/$ length $) \times 100$. The eggshell color was measured with a reflectometer (EQ Reflectometer, York Electronics Centre, York, UK), while the egg-specific gravity was calculated using the method based on the Archimedes principle. The eggshell was washed to remove the adhering albumen and air-dried. The thickness of the eggshell with the 
membranes was measured with a caliper (accuracy 0.001 in, AMES, Waltham, MA, USA), while its weight was measured using a digital balance (Navigator TM, N2B110, OHAUS Corporation, Parsippany, NJ, USA). The albumen weight was calculated by subtracting the weights of the egg yolk and shell from the weight of the egg. The yolk color was estimated using the Roche Colour Yolk Fan, while the Haugh units were measured using designated equipment by the EQM York Electronics Center (Egg Quality Microprocessor, Technical Services \& Supplies Ltd., Dunnington, York, UK). The egg quality parameters were measured at the Laboratory of Animal Husbandry, Faculty of Veterinary Medicine, Aristotle University of Thessaloniki.

\subsection{Oxidative Parameters Analysis}

\subsubsection{Iron-Induced Lipid Oxidation of Egg Yolk}

The oxidative stability was assessed in 12 egg yolks from each treatment sampled at the end of each experimental period (36 eggs/experimental period in total) following iron-induced lipid oxidation. Twelve (12) yolks of each treatment were mixed to create four mixtures of three yolks each. Four 1-g samples from each of the four mixtures were weighed into 50-mL centrifuge tubes, and iron-induced lipid oxidation was carried out with a modification of the method of Galobart et al. [29]. According to that, $0.5 \mathrm{~mL}$ of 5-mM ferrous sulphate and $0.5 \mathrm{~mL}$ of $2-\mathrm{mM}$ ascorbic acid were added to the yolk samples, and the contents of the tubes were vortex-mixed vigorously for $15 \mathrm{~s}$. Following incubation at $37{ }^{\circ} \mathrm{C}$ for either $0,50,100$, or $150 \mathrm{~min}$, all yolk samples were immediately submitted to malondialdehyde (MDA) determination for evaluating the extent of lipid oxidation.

\subsubsection{Evaluation of Lipid Oxidation in Egg Yolk}

The evaluation of lipid oxidation was based on malondialdehyde (MDA) determination using the selective third-order derivative spectrophotometric method developed by Botsoglou et al. [30]. According to this method, the yolk sample (12 egg yolks per treatment) was mixed with $5 \mathrm{~mL}$ of $0.8 \%$ butylated hydroxytoluene (Sigma Chemical, Co., St. Louis, MO, USA) in hexane and $8 \mathrm{~mL}$ of $5 \%$ aqueous trichloroacetic acid (Sigma Chemical, Co., St. Louis, MO, USA). The mixture was homogenized (Ultra-Turrax, Janke \& Kunkel-IKA-Labortechnik, Staufen, Germany) for $30 \mathrm{~s}$ and centrifuged (Hettich Universal1200 ) for $3 \mathrm{~min}$ at $2000 \times \mathrm{g}$. The top hexane layer was discarded, and a $2.5-\mathrm{mL}$ aliquot of the bottom aqueous layer was mixed with $1.5 \mathrm{~mL}$ of $0.8 \%$ aqueous 2 -thiobarbituric acid (Sigma Chemical, Co., St. Louis, MO, USA). The mixture was incubated at $70{ }^{\circ} \mathrm{C}$ for $30 \mathrm{~min}$ and, following cooling under tap water, was submitted to third-order derivative spectrophotometry (Shimadzu, Model UV-160A, Tokyo, Japan). The height of the peak at $521.5 \mathrm{~nm}$ was used for calculation of the MDA concentration in the yolk extracts based on the slope and intercept data of the computed least-squares fit of a freshly prepared standard calibration curve.

\subsection{Microbiology Analysis}

All samples were aseptically collected, placed in sterile bags, and transferred in cool bags to the Laboratory of Microbiology and Infectious Diseases, School of Veterinary Medicine, Aristotle University of Thessaloniki for bacteriological analyses. The detection of Campylobacter and Salmonella was performed according to ISO 10272-1 [31] and ISO 6579-1 [32], respectively. The detection and enumeration of Enterobacteriaceae was performed according to ISO 21528-2 [33]. For Campylobacter detection, three eggshells were separated from their contents and were aseptically placed and weighted in a sterile stomacher bag. A tenfold dilution was obtained by adding an enrichment medium Bolton broth. After homogenization, the samples were incubated in a microaerophilic atmosphere at $37^{\circ} \mathrm{C}$ for $4 \mathrm{~h}$ and then at $41.5^{\circ} \mathrm{C}$ for $24 \mathrm{~h}$. From the enrichment culture, $10 \mu \mathrm{L}$ were transferred and spread in the selective mCCD agar (OXOID) and incubated at $41.5{ }^{\circ} \mathrm{C}$ for $44 \mathrm{~h}$ in the above atmosphere. All plates were examined for the growth of suspected Campylobacter colonies. For Salmonella detection, $25 \mathrm{~g}$ of both eggshells and contents (yolk 
and albumen) of 2 eggs were weighted and pre-enriched in $225 \mathrm{~mL}$ of buffered peptone water (BPW; Biolife, Italy) at $37^{\circ} \mathrm{C}$ for $18 \mathrm{~h}$. Then, $100 \mu \mathrm{L}$ were plated in 3 drops equally spaced onto the surface of Modified Semi-solid Rappaport Vassiliadis agar (MSRV, OXOID) and incubated at $41.5^{\circ} \mathrm{C}$ for $24 \mathrm{~h}$. Plates with no growth were additionally incubated for $24 \mathrm{~h}$. All plates were examined for the growth of white grey colonies with a turbid zone around the droplet. Moreover, $1 \mathrm{~mL}$ of the pre-enriched culture was transferred to 10-mL Muller Kauffman tetrathionate/novobiocin broth (MKTTn-Biolife, Italian S.r.L, Milano, Italy) and incubated at $37{ }^{\circ} \mathrm{C}$ for $24 \mathrm{~h}$. Suspected colonies from the MSRV plates, as well as a loop from MKTTn, was spread to XLD (Merck, Germany) and RAMBACH (Merck, Germany) agar plates. After the incubation at $37{ }^{\circ} \mathrm{C}$ for $24 \mathrm{~h}$, the growth of typical or atypical Salmonella colonies was evaluated. For the detection and enumeration of Enterobacteriaceae, $10 \mathrm{~g}$ of the shell sample was transferred aseptically to $90 \mathrm{~mL}$ of diluent buffered peptone water (BPW). After homogenization, $1 \mathrm{~mL}$ of the initial dilution was transferred to $9 \mathrm{~mL}$ of diluent in the tubes. This resulted in $10^{-2}$ and $10^{-3}$ dilutions. Double-row Petri dishes $(\varnothing 90 \mathrm{~mm})$ were inoculated with a sterile pipette in $1 \mathrm{~mL}$ of the initial dilution, as well as the next 2 decimal dilutions. Approximately $10 \mathrm{~mL}$ of the Violet Red Bile Glucose agar (VRBG) substrate (Biolife, Italian S.r.L, Milan, Italy) was added to each plate. After complete solidification of the material, approximately $10 \mathrm{~mL}$ of the VRBG agar covering layer was added and incubated at $37^{\circ} \mathrm{C}$ for $24 \mathrm{~h} \pm 2 \mathrm{~h}$. Pink to red or purple colonies were counted as Enterobacteriaceae, while 5 colonies from each plate was subjected to further biochemical identification according to the ISO methodology mentioned above.

\subsection{Statistical Analysis}

The data were analyzed using the Statistical Package for Social Sciences software (SPSS 25.0 Version, Chicago, IL, USA). Statistical significance was considered at $p<0.05$, while a statistical trend was considered for those values between $0.05<p<1.0$. The results were presented as the mean \pm standard deviation (SD) where appropriate. Parameters were analyzed with one-way ANOVA, and post-hoc comparisons between treatments were made by Tukey's test. Treatment was included in the model as the fixed factor. In accordance with the recently published study in organic laying hens by van der Heide et al. [34], which consisted of a similar experimental layout as the current study, the laying hen performance data were not subjected to statistical analysis due to a limited number of repetitions ( $n=2$ per treatment), and thus, only descriptive data are presented for years 1 and 2 . The combined laying hen performance data for years 1 and 2 were analyzed for differences between the treatments. The egg quality data, egg lipid oxidation data and eggshell microbiology data were analyzed statistically, considering the sample (egg) as the statistical unit. The egg quality data and egg lipid oxidation were also analyzed with oneway ANOVA. Data on the microbiology analysis of the eggshells and, specifically, of the enumeration of Enterobacteriaceae were analyzed with a nonparametric Mann-Whitney test.

\section{Results}

\subsection{Laying Hen Performance}

The performance parameters during the first experimental period (year 1) are summarized in Table 4 . The laying $\%$ and egg mass were numerically higher in the Con and Sal-1.0\% groups compared to Sal- $0.5 \%$. The average daily feed intake (ADFI) was numerically higher in Sal-1.0\% than Sal-0.5\% and intermediate in the Con group. The feed conversion ratio (FCR) was numerically lower in the Con and Sal-1.0\% groups than Sal$0.5 \%$. The body weight of laying hens did not differ either between treatments at the start or at the end of the experimental period. 
Table 4. Effects of treatments on the performance parameters of laying hens during the 1st experimental period ( $n=2$ per treatment for the laying performance (\%), ADFI, egg mass, and FCR; $n=66$ per treatment for the body weight measurements).

\begin{tabular}{ccccc}
\hline \multirow{2}{*}{ Parameter } & \multicolumn{4}{c}{ Treatments } \\
\cline { 2 - 5 } & Con & Sal-0.5\% & Sal-1.0\% & $p$-Value \\
\hline Laying performance (\%) & $60.56 \pm 6.780$ & $51.95 \pm 11.349$ & $59.86 \pm 7.197$ & na \\
ADFI (g/day) & $104.17 \pm 12.867$ & $101.24 \pm 11.791$ & $105.17 \pm 10.161$ & na \\
Egg mass (g) & $38.25 \pm 4.418$ & $32.32 \pm 6.657$ & $38.45 \pm 3.888$ & na \\
FCR & $2.77 \pm 0.277$ & $3.25 \pm 0.797$ & $2.78 \pm 0.368$ & na \\
Body weight start & $1649.17 \pm 166.24$ & $1631.82 \pm 159.65$ & $1611.59 \pm 167.90$ & 0.424 \\
Body weight 16th week & $1766.78 \pm 197.61$ & $1725.77 \pm 199.93$ & $1755.59 \pm 170.19$ & 0.506
\end{tabular}

Con: hens fed the control diet, Sal-0.5\%: hens were fed the control diet supplemented with $0.5 \%$ of Salvia officinalis L., Sal-1.0\% hens were fed the control diet supplemented with $1.0 \%$ of Salvia officinalis L., and na: not applicable.

The results of the performance parameters during the second experimental period (year 2 ) are summarized in Table 5 . The laying $\%$, ADFI, and egg mass were numerically higher in the Sal-0.5\% compared to the other two groups. The body weights of laying hens did not differ between treatments either at the start or at the end of the experimental period.

Table 5. Effects of treatments on the performance parameters of laying hens during the 2nd experimental period ( $n=2$ per treatment for the laying performance (\%), ADFI, egg mass, and FCR; $n=66$ per treatment for the body weight measurements).

\begin{tabular}{ccccc}
\hline \multirow{2}{*}{ Parameter } & \multicolumn{4}{c}{ Treatments } \\
\cline { 2 - 5 } & Con & Sal-0.5\% & Sal-1.0\% & $p$-Value \\
\hline Laying performance (\%) & $57.72 \pm 4.366$ & $62.89 \pm 4.476$ & $55.49 \pm 5.441$ & na \\
ADFI (g/day) & $111.62 \pm 10.622$ & $117.78 \pm 7.294$ & $110.46 \pm 5.805$ & na \\
Egg mass (g) & $37.75 \pm 3.464$ & $41.44 \pm 3.691$ & $36.51 \pm 3.453$ & na \\
FCR & $2.98 \pm 0.364$ & $2.86 \pm 0.251$ & $3.06 \pm 0.402$ & na \\
Body weight start & $1549.85 \pm 191.46$ & $1519.5 \pm 169.11$ & $1490.30 \pm 138.80$ & 0.128 \\
Body weight 16th week & $1832.69 \pm 188.90$ & $1840.00 \pm 244.49$ & $1789.83 \pm 159.90$ & 0.358 \\
\hline
\end{tabular}

Con: hens fed the control diet, Sal-0.5\%: hens were fed the control diet supplemented with $0.5 \%$ of Salvia officinalis L., Sal-1.0\%: hens were fed the control diet supplemented with $1.0 \%$ of Salvia officinalis L., and na: not applicable.

When investigating the results for both the experimental periods, it was revealed that the egg mass was higher in the Sal- $0.5 \%$ than the Con group, while, in the Sal- $1.0 \%$ group, it was intermediate $(p=0.008)$ (Table 6$)$. The data on the FCR showed a better feed conversion in the Sal- $0.5 \%$ compared to the Con group $(p=0.031)$.

Table 6. Effects of treatments on the performance parameters of laying hens for both the 1st and 2nd experimental periods ( $n=4$ per treatment).

\begin{tabular}{ccccc}
\hline \multirow{2}{*}{ Parameter } & Con & Sal-0.5\% & Sal-1.0\% & $p$-Value \\
\cline { 2 - 5 } & $58.67 \pm 6.15$ & $57.36 \pm 10.08$ & $58.25 \pm 6.43$ & 0.620 \\
Laying performance (\%) & $108.59 \pm 11.59$ & $109.21 \pm 12.70$ & $108.17 \pm 7.36$ & 0.928 \\
ADFI (g/day) & $35.85 \pm 6.37^{\mathrm{a}}$ & $39.60 \pm 4.16^{\mathrm{b}}$ & $36.96 \pm 3.58^{\mathrm{ab}}$ & 0.008 \\
Egg mass (g) & $3.14 \pm 0.80^{\mathrm{a}}$ & $2.77 \pm 0.33^{\mathrm{b}}$ & $2.95 \pm 0.38^{\mathrm{ab}}$ & 0.031 \\
FCR & &
\end{tabular}

Con: hens fed the control diet, Sal-0.5\%: hens were fed the control diet supplemented with $0.5 \%$ of Salvia officinalis L., and Sal-1.0\% hens were fed the control diet supplemented with $1.0 \%$ of Salvia officinalis L. ${ }^{a, b}$ Values sharing different superscripts differ between them significantly at $p<0.05$. 


\subsection{Egg Quality Parameters}

The treatment differences for the egg quality parameters were investigated separately for each year and for each sampling timepoint-namely, weeks 2, 4, 6, 8, 10, 12, 14 , and 16. The results presented here to the overall average values obtained in each experimental period.

The results on the egg quality parameters during year 1 are summarized in Table 7. The egg weights tended to be greater in the Sal- $1.0 \%$ group than the Con $(p=0.087)$. The yolk weight was higher in Sal-1.0\% compared to Con, with the Sal- $0.5 \%$ was intermediate $(p=0.043)$. The shell weight and egg width tended to greater in the Sal-1.0\% than the other two groups ( $p=0.060$ and $p=0.067$, respectively). The albumen and yolk $\mathrm{pH}$ were significantly higher in the Sal- $1.0 \%$ compared to the Con $(p=0.001$ and $p=0.002)$, while the yolk $\mathrm{pH}$ was also higher in the Sal- $0.5 \%$ than the Con group.

Table 7. Effects of the treatments on the egg quality parameters during year 1 ( $n=96$ per treatment).

\begin{tabular}{ccccc}
\hline \multirow{2}{*}{ Parameter } & \multicolumn{4}{c}{ Treatments } \\
\cline { 2 - 5 } & Con & Sal-0.5\% & Sal-1.0\% & $p$-Value \\
\hline Egg weight (g) & $63.52 \pm 5.818^{\mathrm{x}}$ & $63.99 \pm 6.202^{\mathrm{xy}}$ & $64.82 \pm 6.431^{\mathrm{y}}$ & 0.087 \\
Yolk weight (g) & $15.20 \pm 1.660^{\mathrm{a}}$ & $15.30 \pm 1.675^{\mathrm{ab}}$ & $15.50 \pm 1.712^{\mathrm{b}}$ & 0.043 \\
Shell weight (g) & $5.99 \pm 0.724^{\mathrm{x}}$ & $5.97 \pm 0.682^{\mathrm{x}}$ & $6.11 \pm 0.725^{\mathrm{y}}$ & 0.060 \\
Albumen weight (g) & $42.33 \pm 4.671^{\mathrm{y}}$ & $42.72 \pm 5.381$ & $43.15 \pm 5.152$ & 0.268 \\
Shell thickness (mm) & $0.44 \pm 0.039$ & $0.43 \pm 0.038$ & $0.44 \pm 0.036$ & 0.143 \\
Egg length (mm) & $58.06 \pm 2.552$ & $58.38 \pm 2.443$ & $58.52 \pm 2.381$ & 0.138 \\
Egg width (mm) & $43.93 \pm 1.421^{\mathrm{x}}$ & $43.96 \pm 1.488^{\mathrm{x}}$ & $44.24 \pm 1.550^{\mathrm{y}}$ & 0.067 \\
Shape index & $0.76 \pm 0.028$ & $0.75 \pm 0.027$ & $0.76 \pm 0.027$ & 0.363 \\
Shell color & $29.07 \pm 4.927$ & $29.41 \pm 4.348$ & $29.46 \pm 4.964$ & 0.653 \\
Yolk weight & $6.94 \pm 0.988$ & $6.99 \pm 0.827$ & $7.04 \pm 0.792$ & 0.546 \\
Haugh units & $90.45 \pm 9.077$ & $90.62 \pm 10.140$ & $89.28 \pm 10.368$ & 0.327 \\
Albumen pH & $8.62 \pm 0.274^{\mathrm{a}}$ & $8.59 \pm 0.291^{\mathrm{a}}$ & $8.68 \pm 0.214^{\mathrm{b}}$ & 0.001 \\
Yolk pH & $6.13 \pm 0.158^{\mathrm{a}}$ & $6.09 \pm 0.101^{\mathrm{b}}$ & $6.10 \pm 0.068^{\mathrm{b}}$ & 0.002 \\
Yolk color & $6.94 \pm 0.988$ & $7.00 \pm 0.889$ & $7.04 \pm 0.792$ & 0.466 \\
Specific gravity & $1.08 \pm 0.007$ & $1.08 \pm 0.006$ & $1.08 \pm 0.006$ & 0.655 \\
\hline
\end{tabular}

Con: hens fed the control-standard diet, Sal- $0.5 \%$ : hens were fed the control diet supplemented with $0.5 \%$ of Salvia officinalis L., and Sal-1.0\% hens were fed the control diet supplemented with 1.0\% of Salvia officinalis L. $\mathrm{a}, \mathrm{b}$ Values sharing different superscripts differ between them significantly at $p<0.05$. ${ }^{\mathrm{x}, \mathrm{y}}$ Values sharing different superscripts tend to differ between them at $1>p>0.05$.

The results on the egg quality parameters during year 2 are summarized in Table 8 . The majority of the egg quality parameters evaluated were similar between the treatments, and significant differences appeared only for the albumen and yolk $\mathrm{pH}$. Albumen $\mathrm{pH}$ was higher in the Sal-1.0\% group compared to the other two groups and was higher in the Sal- $0.5 \%$ than the Con group $(p<0.001)$. The yolk $\mathrm{pH}$ was higher in both groups supplemented with Salvia officinalis L. compared to the Con group $(p<0.001)$.

\subsection{Oxidative Stability of Egg Yolk}

The results of the extent of lipid oxidation (levels of malondialdehyde, MDA) for year 1 are presented in Table 9. No significant difference was detected between the treatments. 
Table 8. Effects of treatments on the egg quality parameters during year 2 ( $n=96$ per treatment).

\begin{tabular}{ccccc}
\hline \multirow{2}{*}{ Parameter } & \multicolumn{4}{c}{ Treatments } \\
\cline { 2 - 5 } & Con & Sal-0.5\% & Sal-1.0\% & $p$-Value \\
\hline Egg weight (g) & $65.37 \pm 5.497$ & $65.87 \pm 6.411$ & $65.84 \pm 5.037$ & 0.597 \\
Yolk weight (g) & $15.42 \pm 1.226$ & $15.58 \pm 1.819$ & $15.61 \pm 1.468$ & 0.362 \\
Shell weight (g) & $6.13 \pm 0.649$ & $6.16 \pm 0.756$ & $6.18 \pm 0.594$ & 0.695 \\
Albumen weight (g) & $43.82 \pm 4.612$ & $44.13 \pm 5.089$ & $44.04 \pm 4.179$ & 0.787 \\
Shell thickness (mm) & $0.44 \pm 0.035$ & $0.43 \pm 0.034$ & $0.44 \pm 0.0316$ & 0.428 \\
Egg length (mm) & $58.17 \pm 1.958$ & $58.42 \pm 2.408$ & $58.26 \pm 2.087$ & 0.493 \\
Egg width (mm) & $44.62 \pm 1.409$ & $44.70 \pm 1.543$ & $44.77 \pm 1.218$ & 0.586 \\
Shape index & $0.77 \pm 0.025$ & $0.77 \pm 0.026$ & $0.77 \pm 0.025$ & 0.471 \\
Shell color & $25.27 \pm 5.384$ & $25.80 \pm 4.790$ & $25.23 \pm 3.987$ & 0.349 \\
Yolk weight & $7.66 \pm 0.979$ & $7.77 \pm 0.915$ & $7.82 \pm 0.852$ & 0.231 \\
Haugh units & $91.77 \pm 9.992$ & $92.17 \pm 8.034$ & $90.41 \pm 10.431$ & 0.254 \\
Albumen pH & $8.40 \pm 0.293^{\mathrm{a}}$ & $8.48 \pm 0.232^{\mathrm{b}}$ & $8.52 \pm 0.220^{\mathrm{c}}$ & $<0.001$ \\
Yolk pH & $6.01 \pm 0.127^{\mathrm{a}}$ & $6.02 \pm 0.109^{\mathrm{a}}$ & $6.06 \pm 0.208^{\mathrm{b}}$ & 0.001 \\
Yolk color & $7.66 \pm 0.979$ & $7.77 \pm 0.915$ & $7.82 \pm 0.852$ & 0.212 \\
Specific gravity & $1.09 \pm 0.006$ & $1.09 \pm 0.006$ & $1.09 \pm 0.007$ & 0.711 \\
\hline
\end{tabular}

Con: hens fed the control-standard diet, Sal- $0.5 \%$ : hens were fed the control diet supplemented with $0.5 \%$ of Salvia officinalis L., and Sal-1.0\% hens were fed the control diet supplemented with $1.0 \%$ of Salvia officinalis L. ${ }^{\text {a-c }}$ : Values sharing different superscripts differ between them significantly at $p<0.05$.

Table 9. Effects of the treatments on the oxidative stability of egg yolk during year $1(n=12$ per treatment).

\begin{tabular}{ccccc}
\hline \multirow{2}{*}{ Time } & Con & Sal-0.5\% & Sal-1.0\% & $p$-Value \\
\cline { 2 - 5 } & $43.59 \pm 7.749$ & $56.23 \pm 12.571$ & $41.62 \pm 6.538$ & 0.107 \\
$\mathrm{~T}=0 \mathrm{~min}$ & $859.71 \pm 424.689$ & $951.88 \pm 336.77$ & $688.70 \pm 104.288$ & 0.521 \\
$\mathrm{~T}=50 \mathrm{~min}$ & $772.75 \pm 247.486$ & $780.29 \pm 103.399$ & $756.52 \pm 295.707$ & 0.989 \\
$\mathrm{~T}=100 \mathrm{~min}$ & $721.16 \pm 272.843$ & $628.99 \pm 102.299$ & $561.16 \pm 132.086$ & 0.497 \\
$\mathrm{~T}=150 \mathrm{~min}$ &
\end{tabular}

Con: hens fed the control-standard diet, Sal- $0.5 \%$ : hens were fed the control diet supplemented with $0.5 \%$ of Salvia officinalis L., and Sal-1.0\% hens were fed the control diet supplemented with 1.0\% of Salvia officinalis L.

The results of the extent of lipid oxidation for year 2 are presented in Table 10. At $50 \mathrm{~min}$ and $100 \mathrm{~min}$, the lipid oxidation was significantly lower in the Sal-1.0\% group compared to the control one, while it was intermediate for the Sal-0.5\% group $(p=0.034$ and $p=0.038$, respectively). At $150 \mathrm{~min}$, the lipid oxidation was lower in both the groups supplemented with Salvia officinalis L. compared to the control one $(p=0.010)$.

Table 10. Effects of the treatments on the oxidative stability of egg yolk during year 2 ( $n=12$ per treatment).

\begin{tabular}{ccccc}
\hline \multirow{2}{*}{ Time } & \multicolumn{4}{c}{ Treatments } \\
\cline { 2 - 5 } & Con & Sal-0.5\% & Sal-1.0\% & $p$-Value \\
\hline $\mathrm{T}=0 \mathrm{~min}$ & $45.78 \pm 18.961$ & $55.65 \pm 21.167$ & $62.61 \pm 30.821$ & 0.630 \\
$\mathrm{~T}=50 \mathrm{~min}$ & $582.03 \pm 53.818^{\mathrm{a}}$ & $533.33 \pm 59.482^{\mathrm{ab}}$ & $448.67 \pm 66.819^{\mathrm{b}}$ & 0.034 \\
$\mathrm{~T}=100 \mathrm{~min}$ & $585.51 \pm 38.917^{\mathrm{a}}$ & $553.62 \pm 113.305^{\mathrm{a}}$ & $430.15 \pm 48.732^{\mathrm{b}}$ & 0.038 \\
$\mathrm{~T}=150 \mathrm{~min}$ & $731.01 \pm 168.776^{\mathrm{a}}$ & $513.04 \pm 101.913^{\mathrm{b}}$ & $413.33 \pm 33.73^{\mathrm{b}}$ & 0.010
\end{tabular}

Con: hens fed the control-standard diet, Sal- $0.5 \%$ : hens were fed the control diet supplemented with $0.5 \%$ of Salvia officinalis L., and Sal- $1.0 \%$ hens were fed the control diet supplemented with $1.0 \%$ of Salvia officinalis L. ${ }^{a}, \mathrm{~b}$ Values sharing different superscripts differ between them significantly at $p<0.05$.

\subsection{Microbiological Analysis of Eggshells}

The testing of both egg yolk and eggshell revealed the absence of Salmonella spp. and Campylobacter spp. during the first experiment. For the colonies of Enterobacteriaceae, their number per experimental group is presented in Table 11. The total number of 
Enterobacteriaceae was significantly lower in the Sal-1.0\% group compared to the Con $(p=0.032)$.

Table 11. Effects of the treatments on the total number of Enterobacteriaceae of eggshells collected during year 1 ( $n=12$ per treatment).

\begin{tabular}{cccc}
\hline \multirow{2}{*}{ Parameter } & \multicolumn{3}{c}{ Treatments } \\
\cline { 2 - 4 } & Con & Sal-0.5\% & Sal-1.0\% \\
\hline Enterobacteriaceae $(\mathrm{N} / \mathrm{g})$ & $235.0 \pm 147.16$ & $179.0 \pm 154.95$ & $108.8 \pm 130.71$ \\
\hline \multirow{2}{*}{$p$-Value } & Con vs. Sal-0.5\% & Con vs. Sal-1.0\% & Sal-0.5\% vs. Sal-1.0\% \\
\cline { 2 - 4 } & 0.282 & 0.032 & 0.342 \\
\hline
\end{tabular}

Con: hens fed the control-standard diet, Sal- $0.5 \%$ : hens were fed the control diet supplemented with $0.5 \%$ of Salvia officinalis L., and Sal-1.0\% hens were fed the control diet supplemented with 1.0\% of Salvia officinalis L.

Additionally, in year 2, the testing of both egg yolk and eggshell revealed the absence of Salmonella spp. and Campylobacter spp. during the second experiment. For the colonies of Enterobacteriaceae, their number per experimental group is presented in Table 12. The total number of Enterobacteriaceae was significantly lower in the Sal-1.0\% group compared to the Con $(p=0.041)$ and tended to be lower in Sal-1.0\% compared to Sal- $0.5 \%(p=0.087)$.

Table 12. Effects of the treatments on the total number of Enterobacteriaceae of the eggshells collected during year 2 ( $n=12$ per treatment).

\begin{tabular}{cccc}
\hline \multirow{2}{*}{ Parameter } & \multicolumn{3}{c}{ Treatments } \\
\cline { 2 - 4 } & Con & Sal-0.5\% & Sal-1.0\% \\
\hline Enterobacteriaceae $(\mathrm{N} / \mathrm{g})$ & $233.3 \pm 149.74$ & $231.0 \pm 184.89$ & $123.3 \pm 87.00$ \\
\hline \multirow{2}{*}{$p$-Value } & Con vs. Sal-0.5\% & Con vs. Sal-1.0\% & Sal-0.5\% vs. Sal-1.0\% \\
\cline { 2 - 4 } & 0.863 & 0.041 & 0.087
\end{tabular}

Con: hens fed the control-standard diet, Sal-0.5\%: hens were fed the control diet supplemented with $0.5 \%$ of Salvia officinalis L., and Sal-1.0\% hens were fed the control diet supplemented with 1.0\% of Salvia officinalis L.

\section{Discussion}

The development in poultry production systems from traditional cages to enriched cages, free-range systems, and organic systems resulted in multiple challenges for the health and welfare of laying hens. The new systems also increased the efforts to maintain the high performance and health of hens [35]. As asserted in the Introduction, the supplementation of aromatic plants in the diet of laying hens has been a promising practice recently due to their antimicrobial-bacteriostatic and antioxidant properties [10]. However, in organic systems, there is limited evidence regarding the benefits of dietary supplementation of aromatic plants in production output and the health of laying hens [9]. Hence, in the present study, we chose to study the role of a common and distinctive aromatic plant, Salvia officinalis L., on the performance and health of laying hens raised in a commercial organic farm. The results showed that Salvia officinalis L. can improve certain egg quality characteristics subject to several environmental parameters at the farm level that are difficult to control in commercial farms [36]. Moreover, our intention was to avoid major alterations in the daily practices of the farm.

The primary focus of the study was on the egg quality, yolk oxidative stability, and eggshell microbiological counts. Although assessing the effects on the performance parameters was not within the main objectives, we presented performance data to provide more conclusive information for the readers. The practical aspects of the experimental setup of the study obliged us to split the 66 laying hens into two pens that were replicates of each treatment and for each year, resulting in 33 hens per pen and with two pens per treatment. Likewise, in a recent study with organic laying hens, each treatment comprised of two pens with 35 hens in each pen [34]. Similarly, in a study investigating the effects of probiotic 
supplementation in organic laying hens, each treatment comprised three replicates with 20 hens in each replicate [11]. Due to the housing requirements for organic laying hens for outdoor access, such an experimental setup for organic laying hens' feed experiments is inevitable, as housing hens individually in experimental battery cages is not possible. Under these practical considerations, and in agreement with the study of van der Heide et al. [34], we decided not to proceed with the statistical evaluation of the performance data for years 1 and 2. Instead, we assessed the treatment differences for the performance data of both years. Still, this approach enabled the inclusion of four replicate performance data per treatment, which is not an optimum number of replicates for statistical comparisons. Nevertheless, the descriptive results in year 1 showed that the performances of the hens differed between the groups supplemented with Salvia officinalis L. at $0.5 \%$ compared to the controls, with the laying percentage lower and feed conversion ratio higher. This may be attributed to the increased feed intake in the specific group during the transition from the summer to the autumn period [35,37]. It is plausible that the external factors may have been more detrimental in this group compared to the other two groups. Mashaly et al. [38] and Bozkurt et al. [39] reported increased feed intakes in birds during periods of lower environmental temperatures following periods of higher temperatures. During the second experimental period (year 2), the performance parameters were similar between the experimental groups. However, the daily feed intake was higher for hens of all groups compared to the first year. This could be due to the higher levels of humidity noticed during year 2 . Other factors could also be involved for the increased feed intake, especially in the groups supplemented with the aromatic plant, i.e., a positive influence on the feed palatability in the group supplemented with $0.5 \%$ of Salvia officinalis L. but not in that supplemented with $1 \%$ [13]. Bölükbası et al. [40] showed that the inclusion of a $200-\mathrm{mg} / \mathrm{kg}$ extract of Salvia sclarea L. reduced the feed consumption of laying hens. In the latter study, the feed conversion was also improved in the hens supplemented with Salvia sclarea L., but there was no effect on the body weight or laying performance. Moreover, the supplementation of Salvia officinalis L. leaves at $2.5 \%$ in the laying hens' diet did not improve any of the performance parameters [41]. The supplementation of the extract of Salvia sclarea L. in the diets of laying hens did not affect the body weight or laying percentage but improved the feed conversion ratio [40]. The data on the overall experiment revealed that the hens supplemented with $0.5 \%$ of Salvia officinalis L. showed an improved feed conversion compared to the Con group, which corroborated with the previous findings. Meanwhile, a favorable increase in the egg mass for the overall experiment was noted in the Sal-0.5\% compared to Con group, which can be attributed to the improvement of feed conversion in this specific Salvia officinalis L.-supplemented group. According to Çabuk et al. [42], the supplementation of a product containing extracts from various aromatic plants, including Salvia triloba L., in laying hens' diets increased the weight of hens and improved the feed conversion ratio. Özek et al. [43] and Bozkurt et al. [39] used an extract also containing Salvia triloba $\mathrm{L}$. in their experiment but did not find any effects on the performance of laying hens. It should be noted that the previous studies have been conducted in conventional systems and not in organic ones. Laying hens in organic production systems show greater feed conversion rates than those reared under conventional systems [44]. The latter difference is attributed to the greater level of activity and due to a greater variability of the environmental temperature in organic systems [44,45].

In our study, the yolk weight was increased in eggs from hens supplemented with $1.0 \%$ Salvia officinalis L. in both experiments compared to the other two groups. This effect could be attributed to the greater abundance of antioxidant substrates in a specific group, which helped hens to tolerate thermal stress during the production of the yolk [46,47]. The improved digestion and absorption of nutrients in the groups supplemented with Salvia officinalis L. could also have contributed to the higher yolk weight [48-50]. Similarly, Bozkurt et al. [39] reported that the yolk weight was improved when the diets of laying hens were supplemented with an extract containing, among others, Salvia triloba L. In the latter study, the hens were subjected to thermal stress conditions, and the outcome was an 
increase in yolk weight with a concurrent reduction in albumen weight. In the past, other have also investigated the effects of Salvia officinalis L. supplementation on the egg quality characteristics. Loetscher et al. [41] showed that the dietary supplementation of leaves of Salvia officinalis L. at $2.5 \%$ did not improve the egg quality parameters. On the other hand, the supplementation of an extract of Salvia sclarea L. increased the egg weight and Haugh units, while it reduced the yolk percentage [40]. Under thermal stress conditions, the supplementation of an extract containing Salvia triloba L. increased only the egg Haugh unit [42]. Elsewhere, aromatic plant supplementation of the family of Labiatae (oregano, thyme, and rosemary) increased the egg yolk weight [51].

In the present study, it is plausible that laying hens were subjected to chronic heat stress conditions. According to Akbarian et al. [52], chronic heat stress is a combination of high ambient temperatures during a prolonged period. This was probably the case in our study, with the average environmental temperatures being higher during the summer months and especially during the first experimental period. It is known that chronic heat stress induces a depletion of antioxidant reserves in poultry [52], and therefore, it is necessary to replace them by dietary means. Phytochemicals are among those dietary antioxidant ingredients beneficial in chronic heat-stressed poultry [52]. In our study, based on the results of MDA in the egg yolks during year 1, it can be hypothesized that chronic heat stress had a detrimental effect on the antioxidant mechanisms of laying hens supplemented with Salvia officinalis L. However, during year 2, the MDA levels in egg yolks were significantly lower in both groups supplemented with Salvia officinalis L. This finding suggests that chronic heat stress was less pronounced compared to year 1 and that, under these conditions, Salvia officinalis L. supplemented with either $0.5 \%$ or $1.0 \%$ was able to counteract the oxidative stress conditions. Loetscher et al. [41], showed that the supplementation of leaves of Salvia officinalis L. at a level of $2.5 \%$ improved the antioxidative properties of egg yolks. Elsewhere, it was shown that the supplementation of an extract also containing Salvia triloba L. resulted in a significant reduction of MDA in egg yolks and increased the levels of liver enzymes involved in the antioxidative pathways [53]. It is apparent that Salvia officinalis L. supplementation improves not only the antioxidative properties of the eggs but also protects laying hens from pro-oxidative conditions.

The results also showed that the dietary supplementation of Salvia officinalis L. at $1 \%$ significantly reduced the counts of Enterobacteriaceae in eggshells compared to the control group in both experimental periods. This effect could be attributed to the antibacterial properties of the Salvia officinalis L. components, such as $\alpha$-thujone, which had a concentration of $40 \%$ in the plants used in our study. Previous studies showed that the supplementation of $200 \mathrm{mg} / \mathrm{kg}$ of extract of Salvia sclarea L. in laying hen diets reduced the Enterobacteriaceae counts in the feces [40]. These findings are important, as eggs collected from free-range systems were shown to be more contaminated with Enterobacteriaceae counts than those eggs collected from conventional ones [54-56].

\section{Conclusions}

The supplementation of Salvia officinalis L. in powder form, especially at a level of $1 \%$, can improve the oxidative stability of eggs produced by laying hens raised in organic systems. The dietary treatments reduced significantly the counts of Enterobacteriaceae in the eggshells. The potential of the use of Salvia officinalis L. in a powder form in organic laying hens' diets is promising and requires further investigation.

Author Contributions: Conceptualization, D.G. and P.F.; methodology, D.G., D.L., D.F., E.P., and P.F.; formal analysis, D.G. and G.A.P.; investigation, D.G.; data curation, D.G. and G.A.P.; writing—original draft preparation, D.G.; writing — review and editing, D.G., G.A.P., and G.I.A.; and supervision, G.A.P. and P.F. All authors have read and agreed to the published version of the manuscript.

Funding: This research received no external funding.

Institutional Review Board Statement: This study was approved by the General Assembly of the Veterinary Faculty of Aristotle University of Thessaloniki and was part of the PhD research project 
of D.G. The General Assembly of the Veterinary Faculty of Aristotle University of Thessaloniki approved a specific PhD protocol during its decision: 55/27-5-2015.

Informed Consent Statement: Not applicable.

Data Availability Statement: Data are available by the corresponding author upon request.

Conflicts of Interest: The authors declare no conflict of interest.

\section{References}

1. Dunne, C.; Siettou, C. UK Consumers' Willingness to Pay for Laying Hen Welfare. Br. Food J. 2020, 122, 2867-2880. [CrossRef]

2. Larsen, H.; Hemsworth, P.H.; Cronin, G.M.; Gebhardt-Henrich, S.G.; Smith, C.L.; Rault, J.L. Relationship between Welfare and Individual Ranging Behaviour in Commercial Free-Range Laying Hens. Animals 2018, 12, 2356-2364. [CrossRef] [PubMed]

3. Sosnówka-Czajka, E.; Herbut, E.; Skomorucha, I. Effect of Different Housing Systems on Productivity and Welfare of Laying Hens. Ann. Anim. Sci. 2010, 10, 349-360.

4. $\quad$ Pettersson, I.C.; Weeks, C.A.; Wilson, L.R.M.; Nicol, C.J. Consumer Perceptions of Free-Range Laying Hen Welfare. Br. Food J. 2016, 118, 1999-2013. [CrossRef]

5. Sutherland, M.A.; Webster, J.; Sutherland, I. Animal Health and Welfare Issues Facing Organic Production Systems. Animals 2013, 3, 1021-1035. [CrossRef] [PubMed]

6. Jung, L.; Brenninkmeyer, C.; Niebuhr, K.; Bestman, M.; Tuyttens, F.A.M.; Gunnarsson, S.; Sørensen, J.T.; Ferrari, P.; Knierim, U. Husbandry Conditions and Welfare Outcomes in Organic Egg Production in Eight European Countries. Animals 2020, 10, 2102. [CrossRef] [PubMed]

7. Englmaierová, M.; Tůmová, E.; Charvátová, V.; Skřivan, M. Effects of Laying Hens Housing System on Laying Performance, Egg Quality Characteristics, and Egg Microbial Contamination. Czech J. Anim. Sci. 2014, 59, 345-352. [CrossRef]

8. EC REGULATION No1831/2003; Regulation (ec) No 1831/2003 of the European Parliament and of the Council of 22 September 2003 on Additives for Use in Animal Nutrition (Text with Eea Relevance); Official Journal of the European Union: Brussels, Belgium, 2003.

9. Diaz-Sanchez, S.; D’Souza, D.; Biswas, D.; Hanning, I. Botanical Alternatives to Antibiotics for Use in Organic Poultry Production. Poult. Sci. 2015, 94, 1419-1430. [CrossRef] [PubMed]

10. Windisch, W.; Schedle, K.; Plitzner, C.; Kroismayr, A. Use of Phytogenic Products as Feed Additives for Swine and Poultry. J. Anim. Sci. 2008, 86, E140-E148. [CrossRef]

11. Forte, C.; Acuti, G.; Manuali, E.; Casagrande Proietti, P.; Pavone, S.; Trabalza-Marinucci, M.; Moscati, L.; Onofri, A.; Lorenzetti, C.; Franciosini, M.P. Effects of Two Different Probiotics on Microflora, Morphology, and Morphometry of Gut in Organic Laying Hens. Poult. Sci. 2016, 95, 2528-2535. [CrossRef]

12. Puvača, N.; Lika, E.; Cocoli, S.; Kika, T.S.; Bursić, V.; Vuković, G.; Simin, M.T.; Petrovic, A.; Cara, M. Use of Tea Tree Essential Oil (Melaleuca Alternifolia) in Laying Hen's Nutrition on Performance and Egg Fatty Acid Profile as a Promising Sustainable Organic Agricultural Tool. Sustainability 2020, 12, 3420. [CrossRef]

13. Brenes, A.; Roura, E. Essential Oils in Poultry Nutrition: Main Effects and Modes of Action. Anim. Feed. Sci. Technol. 2010, 158, 1-14. [CrossRef]

14. Burt, S. Essential Oils: Their Antibacterial Properties and Potential Applications in Foods-A Review. Int. J. Food Microbiol. 2004, 94, 223-253. [CrossRef]

15. Mitsch, P.; Zitterl-Eglseer, K.; Köhler, B.; Gabler, C.; Losa, R.; Zimpernik, I. The Effect of Two Different Blends of Essential Oil Components on the Proliferation of Clostridium Perfringens in the Intestines of Broiler Chickens. Poult. Sci. 2004, 83, 669-675. [CrossRef] [PubMed]

16. Johny, A.K.; Darre, M.J.; Donoghue, A.M.; Donoghue, D.J.; Venkitanarayanan, K. Antibacterial Effect of Trans-Cinnamaldehyde, Eugenol, Carvacrol, and Thymol on Salmonella Enteritidis and Campylobacter Jejuni in Chicken Cecal Contents in Vitro. J. Appl. Poult. Res. 2010, 19, 237-244. [CrossRef]

17. Grashorn, M.A. Use of Phytobiotics in Broiler Nutrition-An Alternative to Infeed Antibiotics? J. Anim. Feed Sci. 2010, 19, 338-347. [CrossRef]

18. Bozkurt, M.; Hippenstiel, F.; Abdel-Wareth, A.A.A.; Kehraus, S.; Küçükyilmaz, K.; Südekum, K.H. Effects of Selected Herbs and Essential Oils on Performance, Egg Quality and Some Metabolic Activities in Laying Hens-A Review. Eur. Poult. Sci. 2014, 78, 1-15. [CrossRef]

19. Ommati, M.M.; Zamiri, M.J.; Akhlaghi, A.; Atashi, H.; Jafarzadeh, M.R.; Rezvani, M.R.; Saemi, F. Seminal Characteristics, Sperm Fatty Acids, and Blood Biochemical Attributes in Breeder Roosters Orally Administered with Sage (Salvia Officinalis) Extract. Anim. Prod. Sci. 2013, 53, 548-554. [CrossRef]

20. Piesova, E.; Makova, Z.; Levkut, M.; Faixova, Z.; Pistl, J.; Marcin, A.; Levkut, M. The Effects of Sage Extract Feed Supplementation on Biochemical Parameters, Weight of Internal Organs and Salmonella Counts in Chickens. Res. Vet. Sci. 2012, 93, 1307-1308. [CrossRef] [PubMed]

21. Levkut, M.; Marcin, A.; Lenhardt, L.; Porvaz, P.; Revajová, V.; Šoltysová, B.; Blanár, J.; Ševčíková, Z.; Pist, J. Effect of Sage Extract on Alkaline Phosphatase, Enterocyte Proliferative Activity and Growth Performance in Chickens. Acta Vet. Brno 2010, 79, 177-183. [CrossRef] 
22. Farhadi, M.; Hedayati, M.; Manafi, M.; Khalaji, S. Influence of Using Sage Powder (Salvia Officinalis) on Performance, Blood Cells, Immunity Titers, Biochemical Parameters and Small Intestine Morphology in Broiler Chickens. Iran. J. Appl. Anim. Sci. 2020, 10, 509-516.

23. Ryzner, M.; Takáčová, J.; Čobanová, K.; Plachá, I.; Venglovská, K.; Faix, Š. Effect of Dietary Salvia Officinalis Essential Oil and Sodium Selenite Supplementation on Antioxidative Status and Blood Phagocytic Activity in Broiler Chickens. Acta Vet. Brno 2013, 82, 43-48. [CrossRef]

24. Rasouli, B.; Movahhedkhah, S.; Seidavi, A.; Haq, Q.M.I.; Kadim, I.; Laudadio, V.; Mazzei, D.; Tufarelli, V. Effect of Sage (Salvia Officinalis L.) Aqueous Leaf Extract on Performance, Blood Constituents, Immunity Response and Ileal Microflora of Broiler Chickens. Agrofor. Syst. 2020, 94, 1179-1187. [CrossRef]

25. Placha, I.; Ryzner, M.; Cobanova, K.; Faixova, Z.; Faix, S. Effects of Dietary Supplementation with Sage (Salvia Officinalis L.) Essential Oil on Antioxidant Status and Duodenal Wall Integrity of Laying Strain Growers. Pol. J. Vet. Sci. 2015, 18, 741-749. [CrossRef] [PubMed]

26. Van den Dool, H.; Kratz, P.D. A Generalization of the Retention Index System Including Linear Temperature Programmed Gas-Liquid Partition Chromatography. J. Chromatogr. A 1963, 11, 463-471. [CrossRef]

27. Masada, Y. Analysis of Essential Oils by Gas Chromatography and Mass Spectrometry; Halsted Press, a Division of John Wiley \& Sons, Inc.: New York, NY, USA, 1976.

28. Adams, R.P. Identification of Essential Oil Components by Gas Chromatography/Mass Spectrometry, 4th ed.; Allured Publishing Corporation: Carol Stream, IL, USA, 2007.

29. Galobart, J.; Barroeta, A.C.; Baucells, M.D.; Codony, R.; Ternes, W. Effect of Dietary Supplementation with Rosemary Extract and $\alpha$-Tocopheryl Acetate on Lipid Oxidation in Eggs Enriched with $\Omega 3$-Fatty Acids. Poult. Sci. 2001, 80, 460-467. [CrossRef] [PubMed]

30. Botsoglou, N.A.; Fletouris, D.J.; Papageorgiou, G.E.; Vassilopoulos, V.N.; Mantis, A.J.; Trakatellis, A.G. Rapid, Sensitive, and Specific Thiobarbituric Acid Method for Measuring Lipid Peroxidation in Animal Tissue, Food, and Feedstuff Samples. J. Agric. Food Chem. 1994, 42, 1931-1937. [CrossRef]

31. International Organization of Standardization (ISO). ISO 10272-1: Microbiology of the Food Chain-Horizontal Method for the Detection and Enumeration of Campylobacter spp.-Part 1:Detection Method; ISO-International Organization of Standardization: Geneva, Switzerland, 2017.

32. International Organization of Standardization (ISO). ISO 6579-1: Microbiology of the Food Chain-Horizontal Method for the Detection and Enumeration and Serotyping of Salmonella spp.-Part 1:Detection of Salmonella spp.; ISO-International Organization of Standardization: Geneva, Switzerland, 2017.

33. International Organization of Standardization (ISO). ISO 21528-2: Microbiology of the Food Chain-Horizontal Method for the Detection and Enumeration of Enterobacteriaceae_Part 2: Colony Count Technique; ISO_International Organization of Standardization: Geneva, Switzerland, 2017.

34. Van der Heide, M.E.; Johansen, N.F.; Kidmose, U.; Nørgaard, J.V.; Hammershøj, M. The Effect of Deshelled and Shell-Reduced Mussel Meal on Egg Quality Parameters of Organic Laying Hens under Commercial Conditions. J. Appl. Poult. Res. 2021, 30, 100119. [CrossRef]

35. Rodenburg, T.B.; de Reu, K.; Tuyttens, F.A.M. Performance, Welfare, Health and Hygiene of Laying Hens in Non-Cage Systems. In Alternative Systems for Poultry: Health, Welfare and Productivity; Sandilands, V., Hocking, P., Eds.; CABI Publishing: Wallingford, UK, 2012. [CrossRef]

36. Bestman, M.; Wagenaar, J.-P. Health and Welfare in Dutch Organic Laying Hens. Animals 2014, 4, 374. [CrossRef] [PubMed]

37. Leenstra, F.; Maurer, V.; Galea, F.; Bestman, M.; Amsler-Kepalaite, Z.; Visscher, J.; Vermeij, I.; van Krimpen, M. Leistung von Legehennen in Unterschiedlichen Produktionssystemen-Wo Liegen Die Unterschiede Und Wie Kann Man Sie Reduzieren? Resultate von Gruppendiskussionen Mit Legehennenhaltern in Den Niederlanden, Der Schweiz Und Frankreich, Vergleich von Eckdaten Und Modellrechnungen. Eur. Poult. Sci. 2014, 78, 1-10. [CrossRef]

38. Mashaly, M.M.; Hendricks, G.L.; Kalama, M.A.; Gehad, A.E.; Abbas, A.O.; Patterson, P.H. Effect of Heat Stress on Production Parameters and Immune Responses of Commercial Laying Hens. Poult. Sci. 2004, 83, 889-894. [CrossRef] [PubMed]

39. Bozkurt, M.; Küçükyilmaz, K.; Çatli, A.U.; Çınar, M.; Bintaş, E.; Çöven, F. Performance, Egg Quality, and Immune Response of Laying Hens Fed Diets Supplemented with Mannan-Oligosaccharide or an Essential Oil Mixture under Moderate and Hot Environmental Conditions. Poult. Sci. 2012, 91, 1379-1386. [CrossRef] [PubMed]

40. Bölükbasi, S.C.; Erhan, M.K.; Kaynar, Ö. The effect of feeding thyme, sage and rosemary oil on laying hen performance, cholesterol and some proteins ratio of egg yolk and Escherichia coli count in feces. Europ. Poult. Sci. 2008, 72, 231-237.

41. Loetscher, Y.; Kreuzer, M.; Messikommer, R.E. Late Laying Hens Deposit Dietary Antioxidants Preferentially in the Egg and Not in the Body. J. Appl. Poult. Res. 2014, 23, 647-660. [CrossRef]

42. Çabuk, M.; Bozkurt, M.; Alçiçek, A.; Akbap, Y.; Küçükyýlmaz, K. Effect of a Herbal Essential Oil Mixture on Growth and Internal Organ Weight of Broilers from Young and Old Breeder Flocks. South Afr. J. Anim. Sci. 2006, 36, 135-141. [CrossRef]

43. Özek, K.; Wellmann, K.; Ertekin, B.; Tarım, B. Effects of Dietary Herbal Essential Oil Mixture and Organic Acid Preparation on Laying Traits, Gastrointestinal Tract Characteristics, Blood Parameters and Immune Response of Laying Hens in a Hot Summer Season. J. Anim. Feed Sci. 2011, 20, 575-586. [CrossRef] 
44. Lolli, S.; Hidalgo, A.; Alamprese, C.; Ferrante, V.; Rossi, M. Layer Performances, Eggshell Characteristics and Bone Strength in Three Different Housing Systems. Biotechnol. Anim. Husb. 2013, 29, 591-606. [CrossRef]

45. Lara, L.; Rostagno, M. Impact of Heat Stress on Poultry Production. Animals 2013, 3, 356. [CrossRef] [PubMed]

46. Rahimi, S.; Zadeh, Z.T.; Torshizi, M.A.K.; Omidbaigi, R.; Rokni, H. Effect of the Three Herbal Extracts on Growth Performance, Immune System, Blood Factors and Intestinal Selected Bacterial Population in Broiler Chickens. J. Agric. Sci. Tech. 2011, 13, 527-539. [CrossRef]

47. Hashemipour, H.; Kermanshahi, H.; Golian, A.; Veldkamp, T. Effect of Thymol and Carvacrol Feed Supplementation on Performance, Antioxidant Enzyme Activities, Fatty Acid Composition, Digestive Enzyme Activities, and Immune Response in Broiler Chickens. Poult. Sci. 2013, 92, 2059-2069. [CrossRef]

48. Lee, K.-W.; Everts, H.; Kappert, H.J.; Frehner, M.; Losa, R.; Beynen, A.C. Effects of Dietary Essential Oil Components on Growth Performance, Digestive Enzymes and Lipid Metabolism in Female Broiler Chickens. Br. Poult. Sci. 2003, 44, 450-457. [CrossRef]

49. Jang, I.S.; Ko, Y.H.; Yang, H.Y.; Ha, J.S.; Kim, J.Y.; Kim, J.Y.; Kang, S.Y.; Yoo, D.H.; Nam, D.S.; Kim, D.H.; et al. Influence of Essential Oil Components on Growth Performance and the Functional Activity of the Pancreas and Small Intestine in Broiler Chickens. Asian-Australas. J. Anim. Sci. 2004, 17, 394-400. [CrossRef]

50. Franz, C.; Baser, K.; Windisch, W. Essential Oils and Aromatic Plants in Animal Feeding-A European Perspective. A Review. Flavour Fragr. J. 2010, 25, 327-340. [CrossRef]

51. Nadia, R.; Hassan, R.A.; Qota, E.M.; Fayek, H.M. Effect of Natural Antioxidant on Oxidative Stability of Eggs and Productive and Reproductive Performance of Laying Hens. Int. J. Poult. Sci. 2008, 7, 134-150. [CrossRef]

52. Akbarian, A.; Michiels, J.; Degroote, J.; Majdeddin, M.; Golian, A.; de Smet, S. Association between Heat Stress and Oxidative Stress in Poultry; Mitochondrial Dysfunction and Dietary Interventions with Phytochemicals. J. Anim. Sci. Biotechnol. 2016, 7, 1-14. [CrossRef] [PubMed]

53. Bozkurt, M.; Tokuşoğlu, Ö.; Küçükyilmaz, K.; Akşit, H.; Çabuk, M.; Uğur Çatli, A.; Seyrek, K.; Çinar, M. Effects of Dietary Mannan Oligosaccharide and Herbal Essential Oil Blend Supplementation on Performance and Oxidative Stability of Eggs and Liver in Laying Hens. Ital. J. Anim. Sci. 2012, 11, e41. [CrossRef]

54. Parisi, M.A.; Northcutt, J.K.; Smith, D.P.; Steinberg, E.L.; Dawson, P.L. Microbiological Contamination of Shell Eggs Produced in Conventional and Free-Range Housing Systems. Food Control 2015, 47, 161-165. [CrossRef]

55. Jones, D.R.; Anderson, K.E.; Guard, J.Y. Prevalence of Coliforms, Salmonella, Listeria, and Campylobacter Associated with Eggs and the Environment of Conventional Cage and Free-Range Egg Production. Poult. Sci. 2012, 91, 1195-1202. [CrossRef] [PubMed]

56. Hannah, J.F.; Wilson, J.L.; Cox, N.A.; Cason, J.A.; Bourassa, D.V.; Musgrove, M.T.; Richardson, L.J.; Rigsby, L.L.; Buhr, R.J. Comparison of Shell Bacteria from Unwashed and Washed Table Eggs Harvested from Caged Laying Hens and Cage-Free Floor-Housed Laying Hens. Poult. Sci. 2011, 90, 1586-1593. [CrossRef] [PubMed] 